\title{
NMR Characterization of Breslow Intermediates
}

\section{Key words}

carbenes

umpolung

Breslow intermediates

Selected examples:
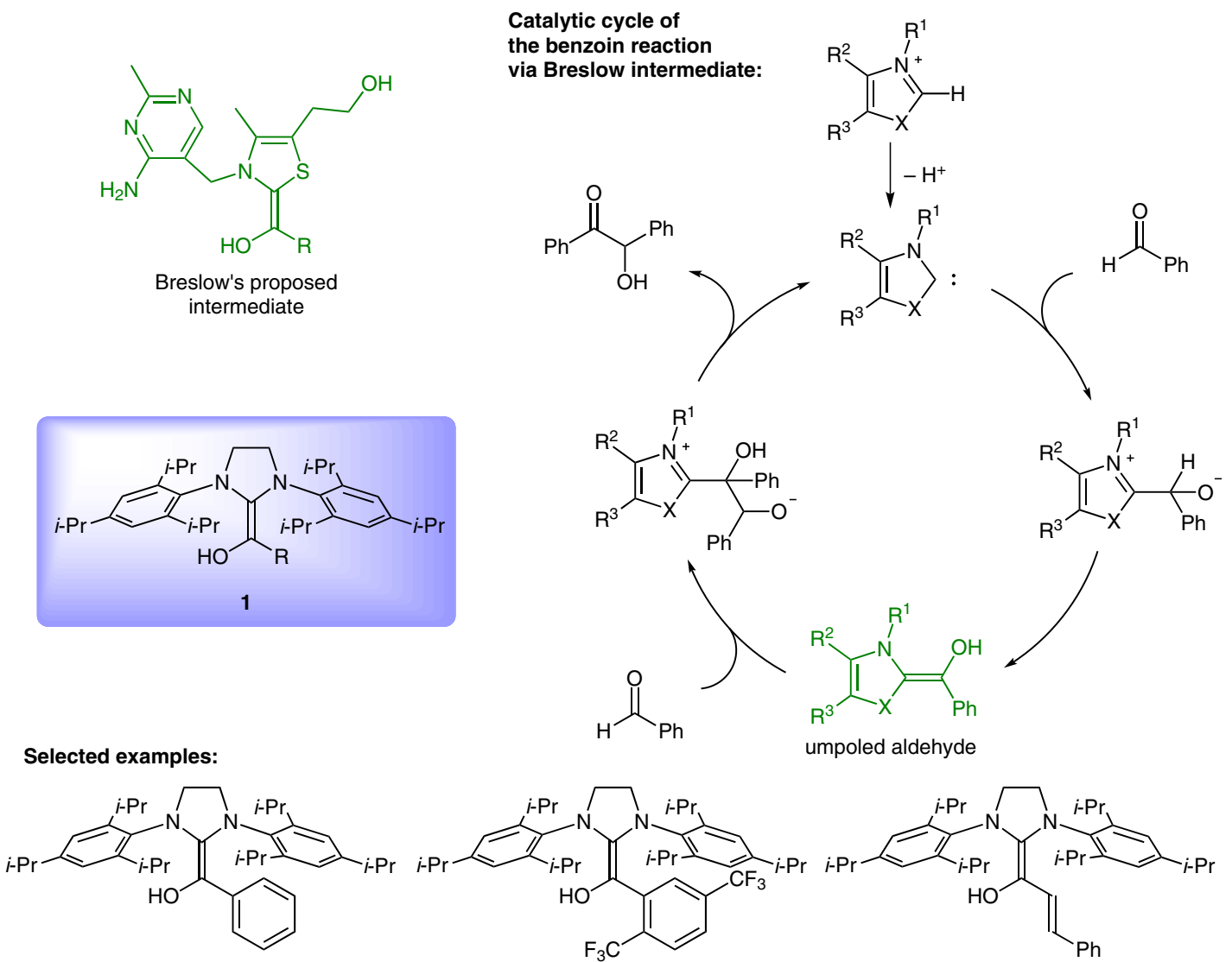

Significance: The generation of 2,2-diamino enols 1 from the corresponding $\mathrm{N}$-heterocyclic carbenes and aldehydes has been reported. Species like $\mathbf{1}$ are commonly invoked as intermediates in aldehyde-umpolung reactions such as the benzoin reaction, and are known as Breslow intermediates. Different Breslow intermediates were characterized by NMR methods for the first time, and are shown to possess the expected benzoin reactivity.

SYNFACTS Contributors: Benjamin List, Ji Hye Kim Synfacts 2013,9(1), 0105 Published online: 17.12.2012 Dol: 10.1055/s-0032-1317899; Reg-No.: B11212SF
Comment: In 1958, Breslow proposed that thiamine-mediated reactions in biochemistry rely on carbene reactivity and invoked the intermediates that today bear his name (J. Am. Chem. Soc. 1958, 80, 3719). In the current report the identification of relatively unreactive Breslow intermediates such as $\mathbf{1}$ by combination of aromatic aldehydes with a saturated carbene was crucial for making the intermediates detectable. More common Breslow intermediates with unsaturated Nheterocyclic carbenes remain to be characterized. For a previous characterization of aza analogues of Breslow intermediates, see: J. Am. Chem. Soc. 2012, 134, 6143. 